\title{
Comparisons Between Tridentate Bis(benzazoles)- pyridine and Bis(benzazoles)triazine Ligands: a Theoretical Study
}

\author{
Mihaiela Andoni, ${ }^{1}$ Jenel Marian Pătraşcu, ${ }^{2}$ Cristina Adriana Dehelean, ${ }^{1}$ Georgeta Maria Simu, ${ }^{1}$ \\ Codruţa Şoica, ${ }^{1}$ Diana Antal, ${ }^{1}$ and Raluca Pop ${ }^{1, *}$
}

\footnotetext{
1 University of Medicine and Pharmacy "Victor Babes" Timisoara, Faculty of Pharmacy, E. Murgu Square 2, 300041 Timisoara, Romania

2 University of Medicine and Pharmacy “Victor Babes" Timisoara, Faculty of Medicine, E. Murgu Square 2, 300041 Timisoara, Romania

* Corresponding author's e-mail address: ralucapop24@gmail.com
}

RECEIVED: April 20, 2015 * REVISED: June 15, 2015 * ACCEPTED: June 24, 2015

\begin{abstract}
Twelve bis(benzazole) structures with potential ligand character were investigated by means of computational chemistry. Global and local reactivity descriptors within DFT (Density Functional Theory) theory (Fukui functions, chemical potential, hardness, electrophilicity index) have been computed at B3LYP/6-31G(d,p) level of theory. NICS(0) (Nucleus Independent Chemical Shift) index computations were employed for the evaluation of the local aromatic character of each heterocyclic moiety. Best results have been reported for the bis(benzimidazole) derivatives. Copper and zinc complexes of the investigated tridentate ligands have been proposed.
\end{abstract}

Keywords: benzimidazole, benzothiazole, metal complexes, tridentate ligands.

\section{INTRODUCTION}

$\mathbf{H}$ ETEROCYCLES like benzimidazole and benzothiazole are ones of the most frequently encountered ligands in transition metals complexes (Figure 1). ${ }^{[1-5]}$

The capacity for coordinating metals (as donor-electron ligand) is due to the presence of the N3 atom (usually denominated as the "pyridine nitrogen"), whose lone pair of electrons is donated to the corresponding metal. The N1 atom (known as the "pyrrole nitrogen" of the benzimidazole moiety) and the $\mathrm{S}$ atom that is present in the benzothiazole ring play no role in the coordination process. The explanation consists of the fact that, the lone pairs of electrons of the heteroatom 1 are involved in the aromatic sextet of the $\pi$-electrons of the rings. ${ }^{[6,7]}$ This way, the N3 atom remains the principal electron-donor in the formation of metal complexes. The ligand character has also been investigated by using theoretical chemistry approaches. ${ }^{[8]}$ Also, there have been reported metal complexes where two benzazole rings are connected by pyridine, ${ }^{[9]}$ leading to structure like 2,6-bis(benzazo-2-yl)pyridine. In certain conformation, these type of structures can be effective tridentate ligands (structures I and II). ${ }^{[10,11]}$ Also, two structures of ligands were the pyridine central ring is replaced by 1,3,5-triazine are proposed (III and IV).

The present paper aims to investigate the properties of this type of ligands, namely the bis(benzazoles) connected by a third heterocyclic ring. Geometric parameters, local aromaticity, global and local reactivity descriptors will be used for the characterization of the structures depicted in Figure 2.

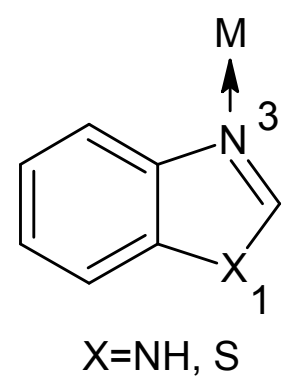

Figure 1. Donor-acceptor bonding in benzazole complexes. 
<smiles>[X]c1ccc2[nH]c(-c3cccc(-c4nc5cc([X])ccc5[nH]4)n3)nc2c1</smiles>

$\mathrm{I}\left(\mathrm{X}=\mathrm{H}, \mathrm{Cl}, \mathrm{CH}_{3}\right)$<smiles>[X]c1ccc2[nH]c(-c3cccc(-c4nc5cc([X])ccc5[nH]4)n3)nc2c1</smiles>

III $\left(X=\mathrm{H}, \mathrm{Cl}, \mathrm{CH}_{3}\right)$<smiles>[X]c1ccc2[nH]c(-c3cccc(-c4nc5cc([X])ccc5[nH]4)n3)nc2c1</smiles>

II $\left(\mathrm{X}=\mathrm{H}, \mathrm{Cl}, \mathrm{CH}_{3}\right)$<smiles>[X]c1ccc2c(c1)[Se]N=C(c1ncnc(-c3nc4cc([X])ccc4[se]3)n1)[Se]2</smiles>

IV $\left(X=\mathrm{H}, \mathrm{Cl}, \mathrm{CH}_{3}\right)$

Figure 2. Heterocyclic ligands I-IV investigated during the present study (where $\mathrm{X}=\mathrm{H}(\mathrm{a}), \mathrm{Cl}(\mathrm{b})$ and $\mathrm{CH}_{3}(\mathrm{c})$, respectively).

We have also proposed the investigation of the changes in the properties of ligands when the central pyridine ring is replaced by s-triazine. The effect of the substituents with electron-withdrawing inductive effect and electron-donor effect (namely $\mathrm{Cl}$ and $\mathrm{CH}_{3}$ groups, respectively) on the benzazole moiety will be also discussed. Geometrical parameters and stability of copper and zinc complexes of the 12 investigated ligands have been evaluated.

\section{Computational Details}

Geometry optimization of the compounds was performed at B3LYP/6-31G(d,p) level of theory. No imaginary frequencies were obtained, proving that all the optimized structures are minima. NICS (Nucleus Independent Chemical Shift) values were calculated using the GIAO (Gauge Independent Atomic Orbital) approach; ${ }^{[12]}$ local and global reactivity descriptors were calculated at B3LYP/6-31G(d,p) level of theory. All the computations have been performed with the G09 W software. ${ }^{[13]}$

For the evaluation of the stability of the complexes, BDE (Bond Dissociation Enthalpy) has been computed as the change in enthalpy of the reaction:

$$
\left[\mathrm{LM}^{2+}\right] \longrightarrow \mathrm{L}+\mathrm{M}^{2+}
$$

Chemical potential $(\mu)$, chemical hardness $(\eta)$ and electrophilicity $(\omega)$ are defined within DFT theory as follows: ${ }^{[14-16]}$

$$
\begin{aligned}
& \mu \approx \frac{\varepsilon_{\text {НОМО }}+\varepsilon_{\text {LUMO }}}{2} \\
& \eta \approx \frac{\varepsilon_{\text {НОМО }}-\varepsilon_{\text {LUMO }}}{2} \\
& \omega=\frac{\mu^{2}}{2 \eta}
\end{aligned}
$$

For the computation of condensed-to-atoms Fukui functions, ${ }^{[17]}$ the following equation has been employed:

$$
f_{k}^{\alpha}=\sum_{\mu \in k}\left|c_{\mu}^{\alpha}\right|^{2}
$$

where $\alpha=$ HOMO orbital, with neglection of the overlap integral.

\section{RESULTS AND DISCUSSION}

\section{Local and Global Reactivity Descriptors for the Ligand Characterization}

The electron-donor capacity of the N3 atom of the benzazole moieties and of the $\mathrm{N} 1$ atom of pyridine and 
Table 1. Condensed Fukui functions ( $\left.f^{-}\right)$(B3LYP/6-31G(d,p))

\begin{tabular}{ccc}
\hline Compound & N3' atoms & N1 atom \\
\hline Ia & 0.0413 & $\approx 1 \cdot 10^{-4}$ \\
Ib & 0.0438 & $\approx 1 \cdot 10^{-4}$ \\
Ic & 0.0452 & $\approx 1 \cdot 10^{-4}$ \\
Ila & 0.0602 & $\approx 1 \cdot 10^{-4}$ \\
IIb & 0.0591 & $\approx 1 \cdot 10^{-4}$ \\
IIc & 0.0636 & $\approx 1 \cdot 10^{-4}$ \\
IIIa & 0.0515 & $\approx 1 \cdot 10^{-4}$ \\
IIIb & 0.0524 & $\approx 1 \cdot 10^{-4}$ \\
IIlc & 0.0539 & $\approx 1 \cdot 10^{-4}$ \\
IVa & 0.0662 & $\approx 1 \cdot 10^{-4}$ \\
IVb & 0.0663 & $\approx 1 \cdot 10^{-4}$ \\
IVc & 0.0685 & $\approx 1 \cdot 10^{-4}$ \\
\hline
\end{tabular}

s-triazine has been investigated. As mentioned earlier, the electron-donor capacity of this type of ligands is due to the $\mathrm{sp}^{2}$-hybridized $\mathrm{N}$ atoms of benzazole and pyridine (or triazine) ring, respectively. The lone pair of electrons of the $\mathrm{sp}^{2}$ $\mathrm{N}$ atoms, which is not involved in ensuring the aromatic sextet of the ring, can interact with electrophilic species like the metal cations. In this regard, the condensed Fukui functions ${ }^{[17]}$ for an electrophilic attack have been computed; the results are presented in Table 1.

The results outline an increased reactivity of the N3atom within the benzothiazole derivatives II and IV compared to the benzimidazole ones; also, it appears that the replacement of the central pyridine ring with s-triazine has a positive influence on the electron-donor capacity of the N3 atom. The presence of the substituents on the benzimidazole moieties leads to enhanced values of the Fukui functions $f$ of the N3 atom both for pyridine and s-triazine ligands. As regards the benzothiazole derivatives, only the presence of the methyl group leads to higher reactivity of the $\mathrm{sp}^{2} \mathrm{~N}$ atom. The values that have been obtained for the $\mathrm{N} 1$ atom of both pyridine and s-triazine ring are most probably due to the presence of the bulky benzazole rings. In order to obtain more information regarding the behavior of the proposed structures I-IV as ligands, other reactivity descriptors like chemical potential, hardness and electrophilicity have been computed.

Global reactivity descriptors are used for an estimation of the properties of a molecule as a whole. The concept of electrophilicity as global reactivity descriptor was first introduced by Parr ${ }^{[18]}$ and represents a measure of the energy stabilization when the system receives an additional charge. Electrophilicity quantifies the tendency of a molecule for accepting electrons; thus, in our case, the electrondonor character of the proposed ligands will be enhanced by low electrophilicity values (Table 2 ).

Lowest electrophilicity values have been obtained for the non-substituted structures la-IVa; it also results that the replacement of the central pyridine ring with s-triazine leads to an increase of the global electrophilicity.

According to the local reactivity descriptors listed in Table 1 (the Fukui functions), s-triazine enhances the electron-donor capacity of the N3 atom. The results of the global electrophilicity contradict the ones obtained when local reactivity descriptors have been employed; it must be taken into account that, the values obtained for the global electrophilicity encounter all the $\mathrm{N}$ atoms of the structures, not only the $\mathrm{N}$ atoms involved in the obtaining of the complex. This way, the increased values obtained for the s-triazine ligands are due to the presence of the other two nitrogen atoms within the triazine ring.

Regarding the presence of substituents, the methyl derivatives Ic-IVc are favored by comparison with the chloro-derivatives Ib-IVb.

Table 2. Global reactivity descriptors (chemical potential, hardness, electrophilicity) computed at B3LYP/6-31G(d,p) level of theory

\begin{tabular}{|c|c|c|c|}
\hline \multirow[b]{2}{*}{ Compound } & \multicolumn{3}{|c|}{ Global reactivity descriptors (eV) } \\
\hline & $\mu$ & $\eta$ & $\omega$ \\
\hline la & -3.619 & 2.314 & 2.830 \\
\hline $\mathrm{lb}$ & -3.971 & 2.121 & 3.717 \\
\hline Ic & -3.589 & 2.106 & 3.058 \\
\hline Ila & -3.969 & 2.347 & 3.356 \\
\hline$\| \mathrm{lb}$ & -4.280 & 2.088 & 4.386 \\
\hline IIC & -4.009 & 2.020 & 3.978 \\
\hline IIIa & -4.216 & 2.028 & 4.382 \\
\hline$\| I I b$ & -4.538 & 1.858 & 5.542 \\
\hline IIIc & -4.189 & 1.865 & 4.704 \\
\hline IVa & -4.493 & 2.047 & 4.930 \\
\hline $\mathrm{IVb}$ & -4.788 & 1.860 & 6.163 \\
\hline IVc & -4.453 & 1.868 & 5.308 \\
\hline
\end{tabular}


Table 3. NICS(0) index, computed at B3LYP/6-31G(d,p) level of theory

\begin{tabular}{ccc}
\hline & \multicolumn{2}{c}{ NICS(0) index } \\
\hline Compound & 5-membered ring of benzazoles & 6-membered ring of benzazoles \\
\hline la & -10.882 & -11.104 \\
Ib & -11.142 & -11.570 \\
IC & -11.032 & -10.833 \\
IIa & -8.696 & -10.290 \\
IIb & -8.871 & -10.659 \\
IIc & -8.079 & -9.959 \\
IIla & -10.987 & -10.388 \\
IIb & -11.329 & -11.010 \\
IIlc & -11.062 & -10.450 \\
IVa & -8.631 & -9.932 \\
IVb & -9.137 & -10.472 \\
IVc & -8.870 & -9.965 \\
\hline
\end{tabular}

Table 4a. Geometrical parameters of the copper complexes

\begin{tabular}{cccc}
\hline$\left[\mathrm{LCu}^{2+}\right]$ & $\mathrm{d}\left(\mathrm{N3}^{\prime}-\mathrm{Cu}\right)(\AA \AA)$ & $\mathrm{d}(\mathrm{N} 1-\mathrm{Cu})(\AA \AA)$ & $\left(\mathrm{N} 1-\mathrm{Cu}-\mathrm{N3}^{\prime}-\mathrm{C9}\right)$ \\
\hline $\mathrm{la}$ & 1.920 & 1.907 & 179.95 \\
$\mathrm{Ila}$ & 1.930 & 1.885 & 179.89 \\
$\mathrm{Ila}$ & 1.949 & 1.888 & 179.90 \\
$\mathrm{IVa}$ & 1.959 & 1.873 & 180.00 \\
\hline
\end{tabular}

Table 4b. Geometrical parameters of the zinc complexes

\begin{tabular}{cccc}
\hline 5 & $\mathrm{~d}\left(\mathrm{N3}^{\prime}-\mathrm{Zn}\right)(\AA)$ & $\mathrm{d}(\mathrm{N} 1-\mathrm{Zn})(\AA)$ & $\left(\mathrm{N} 1-\mathrm{Zn}-\mathrm{N} 3^{\prime}-\mathrm{C9}\right)$ \\
\hline la & 1.949 & 1.986 & 180.00 \\
Ila & 1.976 & 1.959 & 180.00 \\
IIla & 1.978 & 1.976 & 176.32 \\
$\mathrm{IVa}$ & 2.000 & 1.953 & 175.58 \\
\hline
\end{tabular}

\section{Aromaticity Evaluation of the Tridentate Ligands}

There are a number of studies regarding the aromaticity of various metal complexes; ${ }^{[19,20]}$ in the present study, the local aromaticity of the ligands is taken into account. In this regard, computations of $\operatorname{NICS}(0)$ index have been performed; the results are presented in Table 3.

According to the above results, all the heterocyclic rings show aromatic character. It has to be noted that the bis-benzazole pyridine structures have a slight pronounced aromatic character than the 1,3,5-triazine derivatives. As expected, the NICS values obtained for the benzothiazole moiety are lower than the corresponding ones to the benzimidazole ring. In all of the cases, the presence of the chlorine atom leads to highest absolute values of NICS(0) index, proving an enhanced aromatic character.

\section{Characterization of the Metal-complexes Structures}

Metal complexes of type $\left[\mathrm{LM}^{2+}\right]$, where $\mathrm{L}$ are the tridentate ligands $(\mathrm{I}-\mathrm{IV})$ and $\mathrm{M}=\mathrm{Cu}$ and $\mathrm{Zn}$ have been proposed (Figure 3).

The geometric parameters of the two types of metal complexes like the distances $d\left(N^{\prime}-M\right), d(N 1-M)$ and the dihedral angle (N1-M-N3'-C9) are listed in Tables 4a-4b. The results are given only for the unsubstituted complexes of type a (due to the fact that the presence of the $\mathrm{Cl}$ and $\mathrm{CH}_{3}$ groups has no significant influence of the above-mentioned geometric parameters, the data have been omitted).

Copper complexes are characterized by shorter $\mathrm{N}$-metal bond lengths (compared to the zinc complexes); also, their N3'-Cu bonds are slightly longer than the corresponding N1-Cu ones. The replacement of the pyridine 
moiety with s-triazine has led to an increase of the $\mathrm{N}^{\prime}{ }^{\prime}-\mathrm{Cu}$ bond length, together with the shortening of the N1-Cu bond.

Regarding the zinc complexes, the N1- $\mathrm{Zn}$ bond is almost equal or longer than $\mathrm{N}^{\prime}$ - $\mathrm{Zn}$ for the benzimidazole derivatives la and IIla, while the benzothiazoles follow the same trend as the above-described copper complexes. It should be noted the larger deviation of the dihedral angle (N1-Zn-N3'-C9) for the $\mathrm{Zn}$ complexes with s-triazine as the central ring.

\section{Stability of the Metal Complexes}

In order to evaluate the stability of the metal complexes $\left[\mathrm{LM}^{2+}\right]$, the BDE (Bond Dissociation Enthalpy) parameter have been employed. Results are listed in Tables 5-6; the enthalpies of each ligand and corresponding metal complex are given in the Supple-mentary file.

The obtained BDEs are in the range 310.37-393.75 $\mathrm{kcal} / \mathrm{mol}$; highest BDE values have been obtained for the complexes with $\mathrm{CH}_{3}$-substituted benzazoles. Regardless the central six-membered ring and the corresponding metal, the benzimidazole complexes present larger BDE values than the benzothiazole ones. For both copper and zinc complexes with ligand of type II, the chloroderivative (IIb) has a larger BDE values than the corresponding Ila (unsubstituted) ligand. For the other complexes, the general trend of BDE values is: (c) $>$ (a) $>$ (b).

\section{CONCLUSIONS}

The electron-donor character of twelve bis(benza-zoles)pyridine and bis(benzazoles)triazine derivatives and their possible use as ligands have been investigated.

Replacement of the central ring of pyridine with striazine leads to a decrease of the electron-donor character

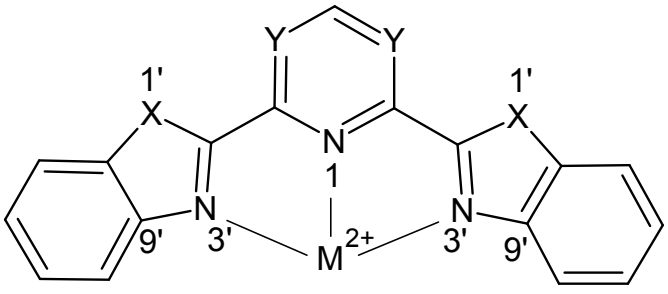

Figure 3. $\left[\mathrm{LM}^{2+}\right]$ structures, where $L$ are the tridentate ligands (I-IV) and $\mathrm{M}=\mathrm{Cu}$ and $\mathrm{Zn}$, respectively.

of the ligands, as suggested by the values of global electrophilicity listed in Table 2. As regards the influence of substituents, the general trend given by the global descriptors of reactivity is $(\mathbf{a})>$ (c) $>$ (b).

Condensed Fukui functions show an enhanced possibility of an electrophilic attack for the N3 atom of the benzazole rings substituted with a methyl group (c). It appears that, the Fukui functions report an increased reactivity of the N3 atom together with the replacement of the pyridine with the s-triazine moiety.

The BDE values computed for the corresponding metal complexes show highest bond strengths for the methylated benzazoles ligands; on the other hand, the enhanced reactivity predicted by the local Fukui functions is associated with lower bond strengths (metal complexes where the central ring is s-triazine have lower BDE values than the ones with pyridine).

The results of $\operatorname{NICS}(0)$ index -as an aromaticity descriptor- show only small differences among the aromaticity of each heterocyclic ring. Most aromatic are the cycles of the chloro-substituted derivatives (b), followed by the unsubstituted species of type (a). As a general trend, more "negative" NICS results led to lower BDE values, so higher

Table 5. BDE (kcal/mol), calculated at B3LYP/6-31G(d,p) level of theory

\begin{tabular}{ccccc}
\hline$\left[\mathrm{LCu}^{2+}\right]$ & \multicolumn{5}{c}{$\mathrm{BDE}(\mathrm{kcal} / \mathrm{mol})$} \\
\hline Substituent & I & II & III & IV \\
\hline $\mathrm{H}$ (a) & 388.70 & 360.62 & 361.82 & 347.87 \\
$\mathrm{Cl}(\mathrm{b})$ & 379.95 & 363.50 & 353.65 & 340.05 \\
$\mathrm{CH}_{3}$ (c) & 393.75 & 380.66 & 368.12 & 353.50 \\
\hline
\end{tabular}

Table 6. BDE (kcal/mol), calculated at B3LYP/6-31G(d,p) level of theory

\begin{tabular}{ccccc}
\hline$\left[\mathrm{LZn}^{2+}\right]$ & \multicolumn{3}{c}{ BDE (kcal/mol) } \\
\hline Substituent & I & II & III & 333.19 \\
\hline $\mathrm{H}(\mathrm{a})$ & 360.82 & 331.58 & 325.32 & 310.37 \\
$\mathrm{Cl}(\mathrm{b})$ & 352.04 & 334.49 & 325.02 & 324.62 \\
$\mathrm{CH}_{3}$ (c) & 366.73 & 351.56 & 340.31 & \\
\hline
\end{tabular}


aromatic character of the ligands leads to lower bond strengths of the metal complexes.

It can be concluded that, the presence of the methyl group on the benzazoles moieties has a positive influence on their behavior as ligands; it leads to enhanced reactivity, a slight lowering of the aromatic character and to the obtaining of metal complexes with higher metal-nitrogen bond dissociation values.

Supplementary Information. Supporting informations to the paper are enclosed to the electronic version of the article at: http://dx.doi.org/10.5562/cca2647.

\section{REFERENCES}

[1] F. Tellez, H. Lopez-Sandoval, S. E. Castillo-Blum, N. Barba-Behrens, Arkivoc 2008, V, 245.

[2] V. H. Arali, V. K. Revankar, V. B. Mahale, P. J. Kulkarni, Trans. Metal Chem. 1994, 19, 57.

[3] S. Liu, W. Cao, L. Yu, W. Zheng, L. Li, C. Fan, T. Chen, Dalton Trans. 2013, 42, 5932.

[4] E. K. Beloglazkina, I. V. Yudin, A. G. Majouga, A. A. Moiseeva, A. I. Tursina, N. V. Zyk, Russ. Chem. Bull. Int Ed. 2006, 55, 1803.

[5] P. Seth, G. Seth, J. Chem. Pharm. Res. 2012, 4, 2771.

[6] G. Li, J. Huang, M. Zhang, Y. Zhou, D. Zhang, Z. Wu, S. Wang. X. Weng, X. Zhou, G. Yang Chem. Commun. 2008, 4564.

[7] G. Muller, J. P. Riehl, K. J. Schlenk, G. Hopfgartner, C. Piguet, J. C. Bunzli, Eur. J. Inorg. Chem. 2012, 12, 3101.

[8] B. S. Kulkarni, A. Tanwar, S. Pal, J. Chem. Sci. 2007, 119, 489.

[9] I. lakovidis, I. Delimaris, S. M. Piperakis, Molecular Biology International 2011.

[10] J. R. Thompson, J. S. Ovens, V. E. Williams, D. B. Leznoff, Chemistry 2013, 19, 16572.

[11] I. G. Dance, D. Isaac, Australian J. Chem. 1977, 30(11), 2425.
[12] D. B. Chesnut, K. D. Moore, J. Comput. Chem. 1985, 10, 648.

[13] Gaussian 09, Revision D.01, M. J. Frisch, G. W. Trucks, H. B. Schlegel, G. E. Scuseria, M. A. Robb, J. R. Cheeseman, G. Scalmani, V. Barone, B. Mennucci, G. A. Petersson, H. Nakatsuji, M. Caricato, X. Li, H. P. Hratchian, A. F. Izmaylov, J. Bloino, G. Zheng, J. L. Sonnenberg, M. Hada, M. Ehara, K. Toyota, R. Fukuda, J. Hasegawa, M. Ishida, T. Nakajima, Y. Honda, O. Kitao, H. Nakai, T. Vreven, J. A. Montgomery, Jr., J. E. Peralta, F. Ogliaro, M. Bearpark, J. J. Heyd, E. Brothers, K. N. Kudin, V. N. Staroverov, T. Keith, R. Kobayashi, J. Normand, K. Raghavachari, A. Rendell, J. C. Burant, S. S. Iyengar, J. Tomasi, M. Cossi, N. Rega, J. M. Millam, M. Klene, J. E. Knox, J. B. Cross, V. Bakken, C. Adamo, J. Jaramillo, R. Gomperts, R. E. Stratmann, O. Yazyev, A. J. Austin, R. Cammi, C. Pomelli, J. W. Ochterski, R. L. Martin, K. Morokuma, V. G. Zakrzewski, G. A. Voth, P. Salvador, J. J. Dannenberg, S. Dapprich, A. D. Daniels, O. Farkas, J. B. Foresman, J. V. Ortiz, J. Cioslowski, D. J. Fox, Gaussian, Inc., Wallingford CT, 2013.

[14] A. Aizman, R. Contreras, J. Chil. Chem. Soc. 2004, 49, 107.

[15] E. Lewars, Computational Chemistry, Kluwer Academic Publishers, Norwell, 2003.

[16] J. Padmanabhan, R. Parthasarathi, U. Sarkar, V. Subramanian, P. K. Chatarraj, Chem. Phys. Lett. 2004, 383, 122.

[17] R. Contreras, P. Fuentealba, M. Galvan, P. Perez, Chem. Phys. Lett. 1999, 304, 405.

[18] R. G. Parr, L. V. Szentpaly, S. Liu, J. Am. Chem. Soc. 1999, 121, 1922.

[19] M. Witwicki, J. Jezierska, J. Phys. Chem. B 2011, 115, 3172.

[20] A. C. Tsipis, C. A. Tsipis, J. Am. Chem. Soc. 2005, 127, 10623. 


\section{Comparisons between tridentate bis(benzazoles)pyridine and bis(benzazoles)triazine ligands: a theoretical study}

\begin{tabular}{|c|c|}
\hline Ligands & Enthalpy* (a.u.) $^{*}$ \\
\hline Ia & -1005.372986 \\
\hline Ib & -1924.579670 \\
\hline Ic & -1083.958118 \\
\hline IIa & -1691.065070 \\
\hline IIb & -2610.270497 \\
\hline IIIc & -1769.644939 \\
\hline IIIa & -1037.491504 \\
\hline IIIb & -1956.697230 \\
\hline IIIc & -1116.076190 \\
\hline IVa & -1723.173577 \\
\hline IVb & -2642.378267 \\
\hline IVc & -1801.759843 \\
\hline
\end{tabular}

- Including thermal corrections and ZPE (Zero Point Energy)

\begin{tabular}{|c|c|}
\hline Copper complexes & Enthalpy* (a.u.) \\
\hline Ia & -2645.205552 \\
\hline Ib & -3564.398250 \\
\hline IIc & -2723.798694 \\
\hline IIa & -3330.852840 \\
\hline IIb & -4250.062857 \\
\hline IIIc & -3409.464657 \\
\hline IIIa & -2677.281189 \\
\hline IIIb & -3596.473904 \\
\hline IIIc & -2755.875921 \\
\hline IVa & -3362.941035 \\
\hline IVb & -4282.133251 \\
\hline IVc & -3441.536266 \\
\hline
\end{tabular}

- Including thermal corrections and ZPE (Zero Point Energy)

\begin{tabular}{|c|c|}
\hline $\mathrm{Cu}^{2+}$ & -1639.213080 \\
\hline $\mathrm{Zn}^{2+}$ & -1778.107014 \\
\hline
\end{tabular}

- Including thermal corrections and ZPE (Zero Point Energy) 


\begin{tabular}{|c|c|}
\hline Zinc complexes & Enthalpy* (a.u.) \\
\hline Ia & -2784.055008 \\
\hline Ib & -3703.247709 \\
\hline Ic & -2862.649570 \\
\hline IIa & -3469.700506 \\
\hline IIb & -4388.910560 \\
\hline IIc & -3548.312210 \\
\hline IIIa & -2816.129503 \\
\hline IIIb & -3735.3222 \\
\hline IIIc & -2894.725531 \\
\hline IVa & -3501.835692 \\
\hline IVb & -4420.979899 \\
\hline IVc & -3580.384189 \\
\hline
\end{tabular}

- Including thermal corrections and ZPE (Zero Point Energy) 